
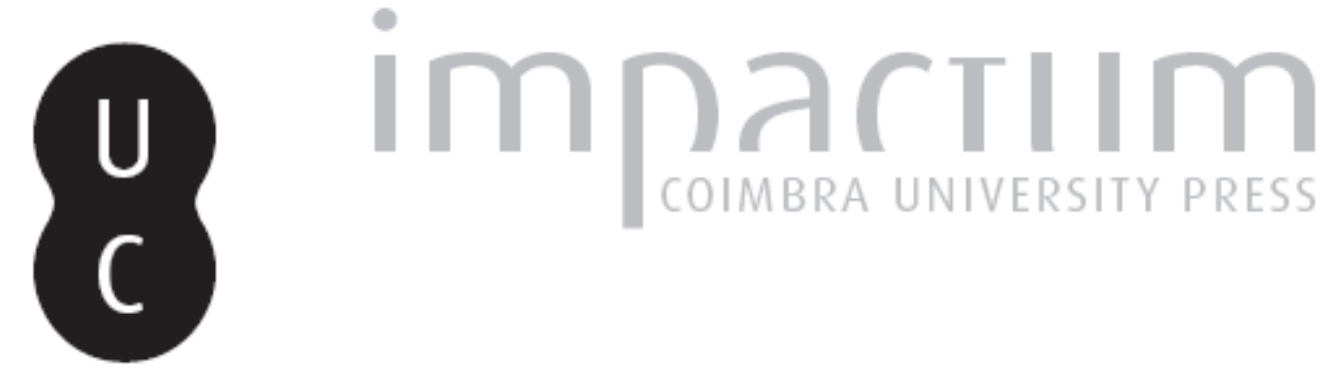

\title{
[Recensão a] KEVIN, Deirdre: Europe in the Media -A Comparison of Reporting, Representation and Rhetoric in National Media Systems in Europe
}

\author{
Autor(es): Martins, Ana Isabel
}

Publicado por: Imprensa da Universidade de Coimbra

URL persistente:

URI:http://hdl.handle.net/10316.2/36717

DOI:

DOI:http://dx.doi.org/10.14195/1647-8622_7_22

Accessed : $\quad$ 26-Apr-2023 03:04:20

A navegação consulta e descarregamento dos títulos inseridos nas Bibliotecas Digitais UC Digitalis, UC Pombalina e UC Impactum, pressupõem a aceitação plena e sem reservas dos Termos e Condições de Uso destas Bibliotecas Digitais, disponíveis em https://digitalis.uc.pt/pt-pt/termos.

Conforme exposto nos referidos Termos e Condições de Uso, o descarregamento de títulos de acesso restrito requer uma licença válida de autorização devendo o utilizador aceder ao(s) documento(s) a partir de um endereço de IP da instituição detentora da supramencionada licença.

Ao utilizador é apenas permitido o descarregamento para uso pessoal, pelo que o emprego do(s) título(s) descarregado(s) para outro fim, designadamente comercial, carece de autorização do respetivo autor ou editor da obra.

Na medida em que todas as obras da UC Digitalis se encontram protegidas pelo Código do Direito de Autor e Direitos Conexos e demais legislação aplicável, toda a cópia, parcial ou total, deste documento, nos casos em que é legalmente admitida, deverá conter ou fazer-se acompanhar por este aviso.

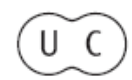




\section{o[s] tempo[s] do[s] medi@}

\section{ESTUDOSDOSÉCULO}

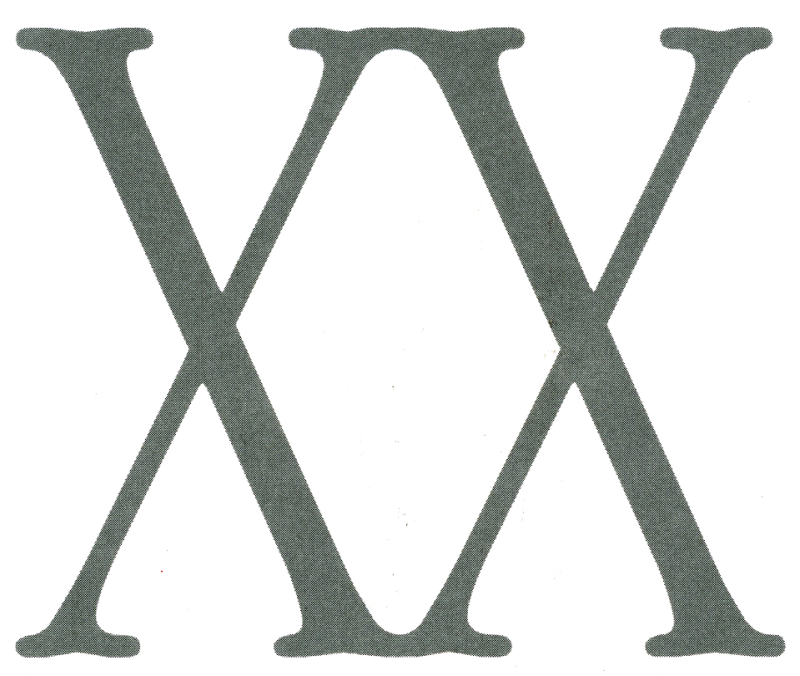

número $7 \cdot 2007$

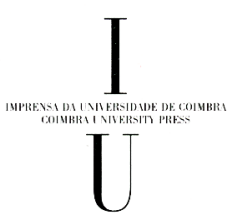


KEVIN, Deirdre: Europe in the Mediat - A Comparison of Reporting, Representation and Rhetoric in National Media Systems in Europe. New Jersey: Lawrence Erlbaum Associates, Publishers, 2003, 203 p.

O livro Europe in the Media, de Deirdre Kevin, resulta de um trabalho de investigaçāo ambicioso nos fins e nos meios: se o título revela um objectivo táo vasto como aliciante (a caracterizaçāo da ideia de Europa enquanto "objecto mediático"), o subtítulo deixa entrever o carácter exaustivo e sistemático da metodologia utilizada (um estudo, em moldes comparativos e transnacionais, das formas de cobertura, representação e retórica desenvolvidas por meios de comunicação de vários países do Velho Continente).

Investigadora do European Institute for the Media (EIM), um think-tank que procura observar, documentar e analisar a evolução dos media e das comunicaçóes a nível europeu, a autora elaborou esta obra numa altura en que as actividades do centro começaram a incidir sobre as implicaçôes políticas e culturais inerentes aos avanças nos campos mediático $e$ comunicativo. Assim, o livro orienta-se para o duplo propósito de "delinear alguns dos mais importantes debates sobre a integraçâa europeia" e "descrever a paisagem mediática onde estes (...) se situam, reflectem e concretizam" (p. XVII). Perceber o papel dos meios de comunicação na vida democrática da Europa e o modo como estes reproduzem o processo de construçáo comunitária será, pois, a preocupaçáo nuclear da pesquisa, em torno da qual gravitam noçōes ligadas à adopçáo de poltticas da UE, à participação cidadã $\mathrm{c}$ à formaçăo de opinião.

Deirdre Kevin impôs-se a tarefa de reunir, num só volume, os resultados de um conjunto de projectos realizados $\mathrm{cm}$ diferentes cenários nacionais - Alemanha, Espanha, França, Holanda, Irlanda, Itália, Polónia, Reino Unido e Suécia. Parecenos que a escolha de naçốes que diferem quer em tamanho, quer em expectativas face à UE - e destaque-se, aqui, o caso polaco, à data o único Estado candidato configura uma sólida e significativa amostra para aferir o tratamento de problemáticas europeias.

Igualmente interessante é a natureza das informaçóes recolhidas: por um lado, material noticioso gerado por mais de 50 meios de comunicação em 8 países, durante dois periodos de uma semana (em Maio e Junho de 1999); por outro lado, dados codificados a partir da programação de mais de 12 canais de televisão pertencentes a 6 Estados, ao longo de um mês e meio (de meados de Maio ao final de Junho de 2000). Um corpus que ilustra, em última instância, a peculiaridade metodológica da obra, tanto em termos quantitativos (mercê do elevado número de media incluídos) como qualitativos (pelo original cruzamento da imprensa nacional e regional, de referência $e$ tablóide - e da TV - pública e privada como base de trabalho).

Os dois capítulos iniciais - o livro contém um total de onze - cumprem uma clara funçăo de enquadramento: o primeiro traça uma breve introduçáo sobre as dinâmicas de integraçâo europeia, sob um pano de fundo cultural e identitário; o segundo apresenta uma abordagem sintética das relaçóes entre os media e a Europa comunitária, sobretudo no que se refere aos sistemas mediáticos nacionais e à hipótese normativa de um Espaço Público europeu.

Estabelecem-se, deste modo, as coordenadas que balizam teoricamente o conteúdo empírico do capítulo III, onde o levantamento de um grupo de indicadores 
quantitarivos (secções e tópicos dominantes) permite esboçar um quadro genérico da cobertura de assuntos europeus nas supracitadas semanas de 1999. Se a principal conclusão deste exercício - rcalidades nacionais fortemente matizadas - não constitui um dado surpreendente, julgamos digna de nota a delimitaçăo entre as noticias relativas à "Europa" em geral e os textos específicos acerca da "União Europeia”. Uma opção, sem dúvida, curiosa, se atentarmos na tendência, cultivada de forma crescente no âmbito desta área científica, para a adopção dos termos como sinónimos para efeitos de contagem.

Nos capítulos IV e V, o olhar analítico da autora distancia-se da superficialidade introdutória para se debruçar sobre dois acontecimentos concretos: respectivamente, as eleiçóes para o Parlamento Europeu (última semana de campanha) e a guerra no Kosovo (entendida enquanto "crise europeia"). Alia-se, portanto, a observação de um escrutínio de cariz supranacional (p. 71) ao estudo de um conflito que, percepcionado como um problema comum, acaba por denunciar algumas marcas essenciais do discurso mediático relativo à Europa e à integraçáo europeia (p. 89). Eventos distintos, é certo, mas complementares no modo como póem a descoberto a função dos media no processo de participação eleitoral, na produção e expressão de identidades, em suma, nas percepçóes públicas de uma realidade tão caleidoscópica como a do continente europeu.

$\mathrm{Na}$ senda desta particularizaçáo, o sexto capítulo foca a questão das notícias relacionadas com temas económicos, sobretudo com a UEM, enquanto o sétimo recupera a temática das referências ao Outro (países e pessoas) nos enunciados mediáticos, conferindo-lhe um destaque bastante mais consistente do que as alusóes soltas e pontuais feitas até este ponto. Deirdre Kevin confirma, aqui, a hegemonia dos "três grandes" - Alemanha, França e Reino Unido - como actores noticiosos e enfatiza a singularidade da visão britânica, invariavelmente céptica no que toca à "Europa económica e política", porém marcada por uma perspectiva laudatória face ao "continente das viagens, das férias, da cultura ou do desporto" (p. 115).

A urgência de contrabalançar as conclusóes decorrentes da análise de conteúdo com práticas jornalísticas reais no palco europeu encontra resposta no capítulo VIII, através de entrevistas a políticos e a profissionais dos media. Estes últimos sublinham a dificuldade de promover uma educação para a Europa susceptível de aumentar a irrisória atenção do público para com as notícias europeias, no reverso da qual se inscreve a actual necessidade de imprimir um "gancho nacional" (p. 132) aos textos publicados.

A descrição genérica (capítulo IX) dos programas televisivos dedicados à Europa, bem como do respectivo conteúdo (capítulo X), corrobora esta propensáo para a nacionalização. Um mês e meio de monitorizaçáo em 6 Estados deu a conhecer a existência de uma grande variedade de formatos, transmitidos na sua maioria por canais públicos. No entanto, denunciou um evidente enquadramento de acordo com o ângulo do país de origem: aponte-se, a título de exemplo, a especial importância do debate europeu na televisão polaca, facilmente explicada por um factor contextual - a futura adesáo deste candidato à UE.

Finalmente, cabe ao capítulo XI o complexo dever de condensar, em pouco mais de quinze páginas, os aspectos mais pertinentes de todo o percurso investigativo. Percorrendo os diversos temas que compóem a moldura teórica deste estudo 
- a identificação política, a cidadania europeia, a ideia de uma Europa cultural, a hipótese de um Espaço Público europeu, entre outros - a autora projecta-os sobre um denominador comum: a heterogeneidade das representaçóes mediáticas da Europa e a consequente dificuldade de configurar uma abordagem universal dos media aos temas europeus (p.167).

Remata, depois, o livro com um grupo de propostas, movidas nāo pela intenção utópica de modificar este cenário, mas pela necessidade real de fomentar a empatia dos cidadáos para com o projecto comunitário e de contribuir para uma democracia europeia verdadeiramente transparente: a criaçāo de um programa de actualidade sobre a Europa, a introdução de outros formatos inovadores (de preferência, em horário nobre) e o estreitamento da cooperação entre os vários canais nacionais (p.180-181). Retoma-se, nesta linha de raciocínio, a tese inicial de Kevin, que considera os media como peça incontornável do puzzle democrático europeu, reiterando-se também o protagonismo concedido à televisäo. No fundo, um sinal dos tempos, quando entramos numa Era em que os progressos ao nível da TV digital e dos meios interactivos vâo impondo novos desafios à delimitação dos espaços comunicativos.

Em suma, estamos convictos de que Europe in the Media se assume como uma investigação académica cuidada e rigorosa, redigida numa linguagem simples e acessível a eventuais leitores menos especializados. Pensamos que o seu interesse se desdobra em duas vertentes:

a) Intema, porque a uma organização lógica e coerente se junta a já referida originalidade do corpus, cuja ousadia (em termos de meios de comunicação e países abrangidos) propicia uma visáo transna- cional bastante completa - condição sine qua non para qualquer exercício sobre uma realidade tão intricada e mutável como a europeia;

b) Externa, pois ao estabelecer uma ponte entre as áreas científicas dos estudos dos media e dos assuntos europeus vem colmatar lacunas numa corrente de pesquisa que, embora em frranca expansão, se encontra ainda numa etapa relativamente embrionária.

Não obstante este conjunto de vantagens, julgamos que a obra não está isenta de problemas. Por um lado, se na plataforma empírica - que dá, sem dúvida, uma reposta eficiente aos imperativos teóricos avançados - reside a força deste trabalho, nela se descobre igualmente a sua maior fragilidade: o grau de complexidade extrema que acaba por atingir, consubstanciado no "mosaico" de conclusóes do capítulo XI. Por outro lado, pese embora a feliz inclusảo da Polónia na lista de países analisados, esta é claramente dominada pelas grandes potências alemã, francesa e britânica, cumprindo-se a pecha académica de deixar na sombra Estados com menor peso político-económico no xadrez europeu (Para quando um texto de fundo sobre Portugal?).

De qualquer modo, Europe in the Media merece um balanço claramente positivo. Longe de diminuírem a validade do livro, estas questóes poderiam ser desenvolvidas de forma a suscitar reflexóes sobre uma área de relevância crescente para todos os investigadores, estudantes, políticos e jornalistas que queiram pensar os novos tempos dos media.

Ana Isabel Martins Bolseira do CEIS20 